\section{MacroMixer: A Spreadsheet Program to Aid Mixing Macronutrients for Solution Culture}

\author{
Osamu Kawabata and Richard A. Criley \\ Department of Horticulture, University of Hawaii, Honolulu, HI 96822
}

Additional index words. microcomputer program, nutrition

\begin{abstract}
MacroMixer, a microcomputer spreadsheet program, offers 15 commonly used nutrient sources for quick formulation of a macronutrient mix in solution culture. The program displays the total concentration of each macro-element and the contribution of each source when the user specifies the desired volume of the mix and the amount of source considered. This program, used with trial and error, eases computational complexity, as sources may contain more than one controlled macro-element.
\end{abstract}

In solution culture experiments, determining the quantity of nutrient sources to dispense in a solution mix is time-consuming. when a source contains more than one controlled element [e.g., $\mathrm{Ca}$ and $\mathrm{N}$ in $\mathrm{Ca}\left(\mathrm{NO}_{3}\right)_{2}$ ], a change made to control one element $(\mathrm{Ca})$ requires an adjustment to the other element $(\mathrm{N})$. Additional adjustments may be necessary for the types of ions, volubility, $\mathrm{pH}$, and cost (Resh, 1989). Since a complex computation can be simplified by using a spreadsheet (Ozminkowski et al., 1991), MacroMixer, a microcomputer spreadsheet program, was developed to ease the computational chore of mixing macronutrients.

Determining a solution mix with MacroMixer is a two-step process (Fig. 1). In the first step, the user specifies the final volume of the mix at the beginning, although it can be changed later. Next, the user specifies the desired concentration (in milligrams per liter) for the primary controlled element in each source in the respective spreadsheet cell. The program computes the weight (volume for liquids) of source required in the mix. For efficiency, we recommend starting with a source that contains two controlled elements. The concentration of the second controlled element in the source will be adjusted later.

In the second step, the weight (or volume) of each source computed in the first step serves as a starting value. The program computes all available elemental concentrations from each source. Totals of all elements in the final solution mix are also computed. The deficit or excess in the second controlled element can be adjusted by adding or reducing a source that

Received for publication 15 Oct. 1992. Accepted for publication 14 June 1993. Hawaii Institute of Tropical Agriculture and Human Resources (HITAHR) Journal series no. 3776 . The use of trade names in this publication does not imply endorsement by HITAHR of the products mentioned nor criticism of those omitted. The cost of publishing this paper was defrayed in part by the payment of page charges. Under postal regulations, this paper therefore must be hereby marked advertisement solely to indicate this fact. contains only the second controlled element. This step can be repeated easily for refining the mix, as an adjustment made to one source is reflected instantly on the source's elemental contributions and also on the totals from all sources. This two-step process allows quick

The program accommodates a maximum of seven sources and seven elements in a formulation of a solution mix. standard computer display (80 columns $\times 25$ lines), while each numeric value holds five significant digits, including one decimal. However, users can increase the limits for more sources and elements. Fifteen sources are incorporated presently in the program. The spreadsheet format hides computational constants and formulae for a clear view of solution composition. The constants (atomic weight, formula weight, purity, and density) are stored in a separate screen, while formulae are stored as cell formats. Thus, users are encouraged to exercise trial and error to achieve the most desirable solution mix.

To demonstrate MacroMixer's use, we duplicated the macronutrients in Hoagland's solution 1 (Hoagland and Arnon, 1950) by entering the recommended sources and elemental concentrations (Fig. 2) in the program. The macro-element composition in the solution mix and the weight of each element delivered by $100 \mathrm{ml}$ of mix are displayed. The contributions of two sources of $\mathrm{N}$ and $\mathrm{K}$ can be observed readily. Modifications cart be made to the final volume, the solution's concentration, and source by entering numbers in the appropriate cells.

We used only four mineral salts for demonstrating Hoagland's solution 1. However, additional sources, including ammonium nitrate, ammonium phosphate, urea, phosphoric acid, 


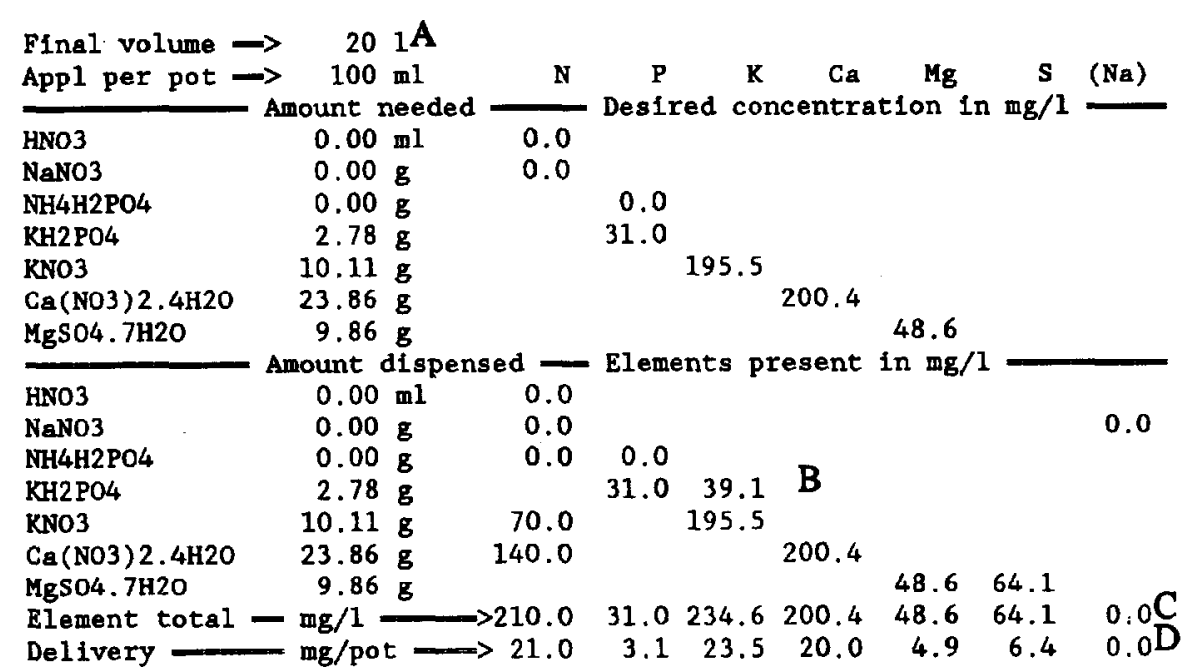

Fig. 2. The macronutrient composition for Hoagland's solution 1 (Huagland and Annon, 1950) as an example of a MacroMixer application. The program displays the amount of each recommended compound needed to make 20 liters of solution mix $(\mathbf{A})$, the element concentrations from each source $(\mathbf{B})$, the total of each element (C), and the weight of each element delivered in $100 \mathrm{ml}$ of solution mix (D). ammonium sulfate, potassium sulfate, potassium chloride, and magnesium nitrate, are incorporated in the program for general use.

MacroMixer requires a microcomputer that runs Lotus 1-2-3 (Lotus Development Corp., Cambridge, Mass.) or compatible spreadsheet programs. A minimum configuration for a DOS computer to run Lotus $1-2-3$ is $256 \mathrm{~K}$ RAM and a floppy disk drive. Instructions for program use are included on the program diskette. Researchers can obtain MacroMixer by sending a self-addressed diskette mailer with a formatted diskette to O.K. or R.A.C.

\section{Literature Cited}

Hoagland, D.R. and D.I. Arnon. 1950. The waterculture method for growing plants without soil. California Agr. Expt. Sta. Circ. 347.

Ozminkowski, R.H., Jr., R.H. Moll, and R.G. Gardener. 1991. QUANPLUS: A spreadsheet for calculation of heritability and generation mean separation. HortScience 26:1086.

Resh, H.M. 1989. Hydroponic food production. 4th ed. Woodbridge Press, Santa Barbara, Calif. 